Article

\title{
Before \#MeToo: Violence against Women Social Media Work, Bystander Intervention, and Social Change
}

\author{
Jordan Fairbairn
}

Department of Sociology, King's University College, London, ON N6A 2M3, Canada; jfairba4@uwo.ca

Received: 28 April 2020; Accepted: 6 July 2020; Published: 15 July 2020

check for updates

\begin{abstract}
High-profile, social-media-fueled movements such as \#MeToo have captured broader public attention in recent years and sparked widespread discussion of violence against women (VAW). However, online prevention work was underway in the years leading up to \#MeToo, as the emergence and proliferation of social media enabled individuals to be increasingly active participants in shaping conversations about VAW. Situated within feminist VAW scholarship and the social-ecological framework of violence prevention, this paper draws from interviews with a cross-section of service providers, public educators, activists, advocates, writers, and researchers to analyze "conversation" as a central theme in VAW prevention work in social media. Results reveal that these conversations take place in three central ways: (1) engaging wider audiences in conversations to raise awareness about VAW; (2) narrative shifts challenging societal norms that support or enable VAW; and (3) mobilization around high-profile news stories. The paper finds that, through these conversations, this work moves beyond individual-level risk factors to target much needed community- and societal-level aspects, primarily harmful social norms that circulate and become reinforced in digital media spaces. Moreover, while bystander intervention has traditionally been approached as an offline pursuit to intervene in face-to-face situations of VAW, this paper argues that we can understand and value these VAW prevention efforts as an online form of bystander intervention. Finally, resource challenges and VAW prevention workers' experiences of harassment and abuse related to their online work highlights a need to strengthen social and institutional supports for this work.
\end{abstract}

Keywords: violence against women; social media; news media; social-ecological framework; prevention; bystander intervention; feminism

\section{Introduction}

The emergence and proliferation of social media has made it a critical tool for public mobilization about violence against women (VAW). This became particularly visible in 2017, where the explosion of the \#MeToo movement (founded by activist Tarana Burke in 2006) drove exponential growth in awareness about women's experiences of sexual violence [1]. While there is still much to be done to pursue structural change [1,2], the \#MeToo movement has been a pivotal time for consciousness-raising and engaging wider audiences in conversations about sexual violence [3]. However, social media-based conversations about VAW had been occurring prior to the takeoff of \#MeToo (for example, see ElSherief, Belding, \& Nguyen, [4] for a summary of key Twitter hashtags 2014-2016). As Mendes et al. [1] (pp. 236-237) explain:

Although \#MeToo is perhaps one of the most high-profile examples of digital feminist activism we have yet encountered, it follows a growing trend of the public's willingness to engage with resistance and challenges to sexism, patriarchy and other forms of oppression via feminist uptake of digital communication. 
This wider movement should also be understood as building on the foundation of a long history of feminist activism and advocacy involving mass media [5-9]. Situated within feminist VAW scholarship and the social-ecological framework of violence prevention $[10,11]$, this study analyzes qualitative interview data from 19 participants to explore the role of social media in their VAW prevention work. Specifically, this paper analyzes the data category of "conversation" as VAW prevention work and finds these conversations take place in three central ways: (1) engaging wider audiences in conversations to raise awareness about VAW; (2) narrative shifts challenging societal norms that support or enable VAW; (3) mobilization around high-profile news stories. This paper also takes up the concept of bystander intervention from the VAW field $[12,13]$ to explore the value of this framework for understanding VAW prevention in social media. Bystander intervention programs aim to move beyond the victim-perpetrator relationship to engage third-party individuals and the community at large in violence prevention. While bystander intervention has traditionally been approached as an offline pursuit to intervene in face-to-face situations of VAW, this paper argues that we can understand and value social media-based efforts as a form of online bystander intervention that moves beyond individual-level risk factors to target community- and societal- level risk factors such as harmful social norms that circulate and become reinforced in social media.

The first part of this paper outlines the context for this study, beginning with key terminology and research findings and describing the social-ecological framework. The historical relationship between VAW prevention activism and mass media is then outlined, followed by a discussion of the growth of bystander intervention work. The second part of this paper presents and discusses results from a qualitative analysis of interviews conducted with VAW prevention workers. These interviews provide a valuable context for understanding the significant social media work done in years prior to the explosion of the \#MeToo movement in 2017. As this study will highlight, social media is an important space for many pre-social media violence prevention strategies (e.g., raising awareness among the general public; challenging sexist and misogynistic attitudes), while also adapting to new contexts (e.g., mobilization around news stories and trending hashtags) to capitalize on high-profile opportunities to resist harmful narratives and contribute feminist understandings to VAW discourse. In doing so, this work targets both individual comments and mass-media produced news content, thus representing the intersection of individual-level risk factors (i.e., attitudes and beliefs) with broader community and societal-level variables (i.e., social norms), an important contribution to VAW prevention. However, consistent with research that has pointed to public backlash to feminism and feminist research generally $[9,14,15]$, VAW prevention workers also experience gendered and sexualized abuse and harassment related to their online work as a significant challenge, pointing to a need to develop and foster additional prevention and support measures.

\section{Research Context}

\subsection{Feminist Approaches to VAW}

Although there are multiple and intersecting forms of VAW, it is used here as an umbrella term to refer to intimate partner violence and sexual violence against women perpetrated by men. The World Health Organization [16] (p. 1) defines intimate partner violence as "one of the most common forms of violence against women and includes physical, sexual, and emotional abuse and controlling behaviours by an intimate partner". This abuse occurs between individuals who are in a current or former intimate relationship, including legal marriages, common-law unions, or dating relations $[17,18]$. Sexual violence is defined as any sexual act, attempt to obtain a sexual act, unwanted sexual comments or advances, or acts to traffic, or otherwise directed against a person's sexuality using coercion by any person regardless of their relationship to the victim, in any setting, including but not limited to home and work [13] (p. 149). Intimate partner violence and sexual violence were brought onto the social agenda in the 1970s by feminist activists and researchers, and have since received a great deal of recognition as a social, legal, and criminal justice issue [19-21]. 
Feminist perspectives on VAW maintain that an examination of gender and power is imperative to understanding violence, and that VAW stems from patriarchal social norms and structures and "attitudes held by individuals and institutions as opposed to some psychopathic sickness on the part of the abuser" [16] (p. 143). Although gender is historically a focus of VAW prevention work, in recent decades feminist theory has evolved to encompass broader intersecting systems of oppression such as race and class [22]. This is primarily due to the work of women of color and other marginalized groups, and perhaps most visible in the contributions of Black feminist theory and critical race theory [23-25].

\subsection{Social-Ecological Framework of VAW Prevention}

The social-ecological model, a widely-used framework for understanding VAW, understands how risk factors occur at individual, relationship, community, and societal levels, and targets prevention efforts accordingly $[10,11,26]$. Ecological understandings of VAW are important because they recognize the interconnectedness of various risk factors of VAW, and allow us to integrate individual level theories (e.g., social learning theory) with societal-level theories such as feminist perspectives [27]. This model, including individual, relationship, community, and societal level factors, is summarized in Table 1.

Table 1. Levels (ecologies) of violence against women (VAW).

\begin{tabular}{ccc}
\hline Level & Includes & Examples \\
\hline Individual & $\begin{array}{c}\text { Biological and personal history factors that } \\
\text { may increase the likelihood that an individual } \\
\text { will become a victim or perpetrator of violence. }\end{array}$ & $\begin{array}{c}\text { Gender; age; attitudes and beliefs } \\
\text { supportive of VAW. }\end{array}$ \\
\hline Relationship & $\begin{array}{c}\text { Factors that increase risk as a result of } \\
\text { relationships with peers, intimate partners and } \\
\text { family members. }\end{array}$ & $\begin{array}{c}\text { Sexually aggressive peers; family } \\
\text { environment characterized by violence; } \\
\text { privileging patriarchal values above } \\
\text { women's safety. }\end{array}$ \\
\hline Commity & $\begin{array}{c}\text { Community contexts in which social } \\
\text { relationships are embedded such as schools, } \\
\text { workplaces and neighborhoods. }\end{array}$ & $\begin{array}{c}\text { Norms tolerant of VAW; weak community } \\
\text { sanctions for perpetrators; lack of support } \\
\text { from police and courts. }\end{array}$ \\
\hline & $\begin{array}{c}\text { Larger, macro-level factors that influence } \\
\text { sexual and intimate partner violence such as } \\
\text { gender inequality, belief systems, societal } \\
\text { norms and economic or social policies. }\end{array}$ & $\begin{array}{c}\text { Norms supportive of VAW; male } \\
\text { laws and policies related to sexual violence } \\
\text { and gender equality. }\end{array}$ \\
\hline
\end{tabular}

Adapted from The World Health Organization [28] and Johnson and Dawson [27].

Interdisciplinary and intersectoral public health approaches based on the ecological framework are increasingly being used in VAW prevention efforts [28]. Here, prevention strategies are classified into three types: primary prevention aims to prevent violence before it occurs (e.g., educational programming in schools and/or through social media); secondary prevention focuses on immediate responses to violence (e.g., health care services or treatments following violent victimization); and tertiary prevention attends to long-term care related to experiences of violence (e.g., rehabilitation and reintegration) and attempts to lessen trauma or reduce long-term disability associated with violence [11]. Until recently, primary prevention has been "relatively neglected" in the field of VAW prevention, with most resources directed towards secondary or tertiary prevention [28]. Primary prevention strategies are essential to long-term approaches to reducing VAW, and changing attitudes is a critical but elusive piece of prevention work [27]. Without attitudinal change (e.g., VAW is never acceptable), other prevention efforts (e.g., changing social norms, legislation, front line services) are less likely to be effective (or to be created in the first place).

This study focuses on those engaged in primary prevention in social media contexts. Social media is defined as "the wide range of Internet-based and mobile services that allow users to participate in online exchanges, contribute user-created content, or join online communities" [29] (p. 1). The development and growth of social media such as Facebook (created in 2004), YouTube (2005), Twitter (2006), and Instagram (2010), and general proliferation of apps, blogs, and wikis demonstrate 
how online sharing and collaboration have become principal components of an increasing number of initiatives. As these sites have become central to conversations about social issues, VAW prevention work has also evolved and expanded. Historically, anti-violence work has focused on reducing risk among potential victims and perpetrators [12]. In recent years, prevention approaches have evolved, from treating men simply as perpetrators of violence against women and girls or as allies of women in its prevention, to approaches that seek to transform the relations, social norms, and systems that sustain gender inequality and violence [30] (p. 1).

Specifically, effective programs include critical discussion about gender relationships and the acceptability of violence $[30,31]$. This approach is consistent with a social-ecological understanding of violence that views relational, community, and social prevention strategies, in addition to individual interventions, as essential to eliminating VAW [10,26], and with feminist approaches that emphasize the entrenchment of social and cultural phenomena such as sexism, misogyny, racism, and patriarchy as obstacles to VAW prevention [22,27,32].

\subsection{Feminism, VAW Prevention, and Media}

Social media encompass both traditional media (e.g., news media stories) as well as user-generated content (e.g., individual tweets) in digital spaces. Thus, it is helpful to consider VAW prevention in traditional media in relation to how social media work mobilizes these efforts. In recent decades, mass media representations have garnered significant feminist attention as an important space for understanding and shaping attitudes and beliefs surrounding VAW. These critiques have centered on the role of mainstream media in perpetuating myths and stereotypes surrounding VAW that potentially impede social and political progress to address this violence [33]. Specifically, these critiques problematize patterns observed in mass media portrayals of VAW, such as: (1) relying on rape myths [34-36]; (2) focusing on perpetrator stress (financial, mental or physical health) as an explanation for domestic violence [37,38], (3) framing domestic violence as an unpredictable private tragedy or isolated incident $[39,40],(4)$ emphasizing the spontaneous, "out of the blue" nature of violence by an otherwise ordinary individual [17,41], (5) trivializing violence [42]; (6) subtle or overt victim blaming $[43,44]$ and (7) using primarily official news sources such as police and other criminal justice officials without including advocates and researchers [33,45].

News portrayals are both reflective of social norms and play a role in reproducing them, much like individual attitudes and beliefs $[38,46,47]$. Yet unlike individual attitudes and beliefs, news coverage has an authority of being purportedly objective and telling the true story of events; thus, these portrayals may be readily accepted as fact, despite harmful representations (e.g., victim-blaming, sensationalizing violence) [33] that function as a "technology of violence" with discursive and material effects [48] (p. 35). Misrepresentations may inflict psychological and emotional harm on survivors of violence and their families [49] and miss the opportunity to be a source of public education (e.g., including information on early risk factors and/or helpline information) and positively influence public policy [45]. Because of this, the news portrayals and the public conversations that surround these events are important areas for societal change.

Numerous advocacy organizations have developed media guides and toolkits for reporting on VAW [50-53]. Research and advocacy work in this area is significant because it is part of a broader climate that recognizes harm associated with media sexism and misrepresentation [32,46,54], and demands gender equity in media more broadly $[55,56]$. Solely critiquing media representations is no longer sufficient for change, and scholars and activists have additional resources and networks at their disposal to bridge critique and action. This relationship has continued to evolve as, within social media, advocates can now intervene more directly in narratives (i.e., post, tweet, or publish their own analysis in real time and for broader audiences) rather than (or in addition to) writing a letter to the editor or publishing a best practices guide. As Kingston [57] (p. 293) explains, social media are increasingly sites of struggle over control, surveillance, and monetization, as well as sites of struggle over meaning, representation, 
and participation. Thus, there is a serious need for more feminist analysis and intervention in the politics of visibility and participation in these new media channels.

Lokot [58] explains that feminist activism online has found much success in building networks that critique and disrupt dominant discourses, construct counternarratives, and connect conversations around specific events to broader feminist issues. Korn and Kneese [59] (p. 708) reiterate the value of discourse and narrative in public forums and their potential for affecting structural change:

Social media platforms create public forums where feminists may collectively create discourses apart from the dominant narrative. These counter-publics may in turn garner attention, thus having the capacity to alter institutional policies in physical locations, like universities and workplaces.

The shifting media landscape presents new opportunities as well as challenges for VAW prevention work. Conversations online frequently occur around current events; the comments sections of news stories, for example, frequently contain victim-blaming and questioning statements, as well as perpetrator-supportive statements [60]. Social media can be sites of resistance for challenging rape culture $^{1}[1,4,61]$, however, scholars have also documented emerging and shifting forms of online sexual abuse involving social media [62-64]. Thus, social media presents additional opportunities to move beyond individual-level efforts to engage wider communities in violence prevention.

\subsection{Beyond Victims and Perpetrators: The Growth of Bystander Intervention}

Bystander intervention programs aim to move beyond the victim-perpetrator relationship to shift focus to bystanders, generally defined as "third party witnesses to situations where there is high risk of sexual violence" [12] (p. 3). Bystanders are recognized as a key to prevention because they can make the situation worse by supporting or ignoring behaviors, or can make the situation better by intervening in safe, nonviolent, and prosocial ways $[12,65]$. Bystander intervention, then, can also be thought of as creating "upstanders"2 (a term with roots in genocide studies; see Minow [66]). While the concept of upstanders is similar in terms of understanding the active nature of interventions to speak out against injustice, this paper uses bystander intervention in order to ground this work in and contribute to existing VAW literature, in particular scholarship that considers bystander intervention in the context of social-ecological theory [67] as well as social media [68,69].

For the most part, bystander intervention programs have focused on individuals in face-to-face social settings (e.g., school, parties, public transit) where the risk of violence appears imminent. However, bystander intervention can also focus on less immediate, low risk situations. For example, McMahon and Banyard [12] (p. 9) note that media portrayals are an opportunity for bystander intervention:

Another type of reactive bystander opportunities can be labeled low risk, which can be defined as situations in which negative attitudes toward women and/or sexual violence are expressed, but do not pose immediate or high risk of harm to potential victims of sexual assault. These bystander opportunities address the lower side of the continuum of sexual violence behaviors, such as calling out sexist language, questioning media portrayals that objectify women and girls, challenging the use of pornography, and confronting friends who rank girls' appearances.

Bystander intervention demonstrates promising potential for reducing sexual violence through face-to-face programming in physical world settings [70] as well as within traditional media (e.g., poster

1 Rape culture refers to an environment where sexual violence is expected, tolerated, and/or encouraged, and where women and girls are held responsible for their safety and/or blamed for their victimization [1].

2 According to Minow [66] (pp. 817-818), "an upstander may speak out publicly against bigotry and injustice. An upstander may be a whistle-blower, who exposes wrongdoing in the hope of stopping it. An upstander may resist the temptations of silence and passivity by expressing and offering support directly to victims of bigotry and injustice. An upstander may provide immediate aid to victims of bigotry and injustice through physical rescue or other help ... An upstander may speak out publicly or may instead engage in secret resistance. An upstander may rescue individuals who are in danger-through secret or overt actions." 
campaigns) [65]. However, research has only recently focused on bystander intervention online [68,69], and this work focuses primarily on reactive interventions for individual acts of violence (e.g., online harassment, stalking). Bystander behaviors can be thought of as reactive or proactive; reactive bystander behaviors are where a person intervenes in a situation that can lead to violence, and proactive bystander behaviors are when a person takes an action that promotes social norms that do not accept violence [71] (p. 5). The growth and popularity of social media has shifted many social interactions online as well as driven shifts in how news stories are reported and disseminated [72], thus expanding possibilities for proactive bystander behaviors.

\section{Materials and Methods}

\subsection{Participants}

Data for this paper are drawn from 19 interviews conducted with a cross-section of service providers, public educators, activists, advocates, writers, and researchers who are engaged in VAW prevention work ("VAW prevention workers") from Canada or the United States. Exploratory interviews were conducted in 2012 and 2013 with four participants based on the author's observations of their online VAW advocacy and education work; 15 additional interviews were conducted in late 2014. While social media has changed since 2014 (for example, the growth in the popularity of Instagram), the specific social media sites that participants almost exclusively discussed (Facebook and Twitter $)^{3}$ are still widely used among the public as well as activists and news organizations. Moreover, this period represents an important juncture for developing understanding of the value of digital feminist activism broadly [1] as well as a site for VAW prevention in particular $[58,59,73,74]$.

The majority (13) of these 15 participants were recruited from a survey $(\mathrm{N}=109)$ on social media and VAW prevention conducted in early 2014 as part of the author's larger research project ${ }^{4}$. Thus, participants were not a random sample, but were found through nonprobability sampling [75]. Such sampling is appropriate, given that this study seeks to gain a deeper understanding into the perspectives and work of those already committed to VAW prevention, rather than generalizing to the population at large. In addition to survey recruitment, two additional participants were recruited based on referrals from other participants and the author's observations of their extensive engagement within social media. Generally, 15 or more interview participants is an acceptable sample size for qualitative research [76,77]. Although each respondent had unique perspectives and experiences with VAW prevention work, themes related to their social media work were clear and no new themes were emerging after 19 interviews. Given this, the author concluded saturation of data, where "the same themes reoccur, or research participants report similar views and experiences" [78] (p. 405). This was also confirmed through constant comparative methods [79] to refer back to themes from data collected as part of the larger study [80].

To be interviewed, potential participants had to be doing VAW work involving social media and working primarily in Canada or the United States. Primary roles for interview participants included: directors or program managers within anti-violence organizations $(\mathrm{N}=4)$; communications directors

317 participants use Facebook in their work, 15 use Twitter.

4 The survey was sent to a list of 380 potential participants assembled from: 1) VAW organizations and service providers where email addresses were publicly-available; 2) academics/researchers and government agencies with publicly-available email addresses identified as part of a larger literature review and policy scan on VAW research and prevention programming; 3) individual and organization contact drawn from a Google alert for "Canada violence against women" and "social media violence against women" for fourteen months prior to the launch of the survey. Additionally, the author posted the survey link on Twitter as well as through two listserves whose hundreds of members include feminist activists, advocates, researchers, academics, journalists, and policy analysts (among other roles). While by no means exhaustive, this initial process represented a solid starting point from which to snowball sample for additional participants. When circulating this invite, the author requested that participants also circulate the survey among their networks in order to get broader distribution into local networks that may not have prominent online presence and/or who would perhaps be more likely to respond if they received the survey invitation from a known contact. 
or managers for non-profits $(\mathrm{N}=2)$; activists and public educators $(\mathrm{N}=6)$; journalists and writers $(\mathrm{N}=5)$, and researchers/academics $(\mathrm{N}=2)$. All individuals identified VAW prevention as a significant component of their work. All participants in this sample are women, and their age breakdown was as follows: 16 percent $(\mathrm{N}=3)$ were between the ages of $18-24 ; 42$ percent $(\mathrm{N}=8)$ were $25-34 ; 16$ percent $(\mathrm{N}=3)$ were $35-44$; and 32 percent $(\mathrm{N}=6)$ were $45-54$ years of age. The majority of participants live in urban areas: 11 out of 19 participants (58\%) live in cities over 100,000 people; 5 (26\%) live in communities with 30,000 to 100,000 people, and 3 (16\%) live in cities of less than 30,000.

\subsection{Interviews}

Qualitative interviewing is a historically important method of feminist research [81]. A qualitative interview is described as follows:

An interaction between an interviewer and a respondent in which the interviewer has a general plan of inquiry but not a rigid set of questions that must be asked in particular words in particular order. [82] (p. 332)

The interview approach for this study was grounded in the feminist methodological principles that (1) beginning from a point of individual's voices and experiences will reveal greater understanding of broader social and political relations, [83,84]; and (2) gender (and thus, gender-based violence or VAW), in addition to being an individual attribute, is also a social structure. Risman [84] (p. 431) argues that the common pursuit of feminism is "to situate gender as embedded not only in individuals but throughout social life". Conceptualizing gender, and VAW, in this manner enables us to understand myths, misrepresentation, and misogyny in social media as more than individual issues. As such, this study aims to describe and validate participants' experiences working in social media and to place these in a larger context of VAW prevention work.

Interviews were semi-structured, meaning they were guided by a set of key exploratory questions: (1) Could you describe your work related to VAW in social media (2) What social media sites do you use the most? Can you tell me about how you use each of them differently; (3) Can you tell me a bit more about what prevention involves related to your social media work? (i.e., how you view prevention in this realm; is it different than offline work?); (4) Could you tell me about some of the interactions and initiatives you have experienced on social media? (Example of positive/successful? Example of negative/not successful?); (5) What would you do with social media (or change about social media) pertaining to VAW prevention if you could do anything? Additional probing or clarification questions were asked as needed, including drawing from participants' websites and/or social media profiles (e.g., "I see from your website you use Instagram. Could you tell me about that?"). Interviews took place in person $(\mathrm{N}=3)$, by phone or Skype voice call $(\mathrm{N}=10)$, by Skype or Google Hangout with camera $(\mathrm{N}=4)$ or by Google chat (text only) $(\mathrm{N}=1) .{ }^{5}$ Interviews ranged in length from 21 minutes to 1 hour and 35 minutes, and the average interview was 56 minutes long. All interviews were recorded with permission, transcribed, and coded to identify key themes (discussed further shortly).

\subsection{Analytical Process}

Each interview was transcribed and coded using NVivo qualitative analysis software using a combination of coding and memoing. Coding involves "the development of concepts and categories in the recognition and ordering of themes", while memoing is "the writing of notes and commentaries concerning ideas, patterns, and themes that occur to the researcher in the process of reading and coding data" [82] (p. 381). ${ }^{6}$ Participants use social media for a variety of VAW prevention-related objectives

5 To accommodate one interviewee's request, one interview was conducted in writing by Google chat in synchronous communication. This interview was approximately 90 minutes in length.

6 For further discussion of the coding process, see Fairbairn [80]. 
[see 80 for further discussion]. To contribute to recent work highlighting the importance of hashtag feminism $^{7}$ and other conversation-based feminist activism online $[1,3,4,58,60,73,74]$, the analysis focuses on the data theme "conversation". This theme is particularly salient to timely discussions of \#MeToo and broader social change, and was the most frequently-coded theme in the data overall (the term was used 94 times throughout 18 of 19 interviews).

In writing up the results, the author continuously referred to the coded interview data to ensure that interpretations and organization of the interview findings remained grounded in participants' words. Nonetheless, at the stage of data analysis, the researcher has a great deal of power [85], because they are the narrator who is authoring a document that is "structured primarily by a researcher's purposes, offering a researcher's interpretations registered in a researcher's voice" [86] (p. 114). To mitigate this power, the analysis relies on participants' own words to describe and illustrate research findings [87]..$^{8}$

\section{Results}

\subsection{Engaging Wider Audiences and Raising Awareness}

Expanding conversations about VAW and garnering attention to its prevalence is an important goal for participants. Some view social media as a place to start a conversation about a topic that has historically been a private issue rather than a public conversation. For example, one NGO director states that

because we are only a small project a lot of this is learning what people would want from us, because violence against women, we're talking about topics that are pretty much always conversation stoppers, right?

There is a sense among participants that social media is an effective way to push forward uncomfortable conversations about VAW, and to interject feminist research and advocacy into platforms where this knowledge may not be the norm. For example, one advocate working at an NGO explains that social media can help to push stories and conversations into a more central public view:

I think [about] the ways in which we can have those conversations. So I think that, you know, rape culture and social media brings two-sides of the story at the forefront in public. And that's where some really unintelligent conversations happen, and some really intelligent conversations happen. I think of Anita Sarkeesian, ${ }^{9}$ and her Ted Video ... [that] started off this conversation ... I think another example is the \#WhyIStayed ${ }^{10}$ Twitter campaign. It starts to bring several conversations to light.

There is a two-step process to this work, where content created to raise awareness about VAW (videos, hashtag campaigns) may be produced and distributed in social media, which then provides the space to connect and further discuss the issues raised. In addition to engaging the general public, this social media content enables participants to engage with like-minded organizations and raise awareness collectively, as one participant explains:

7 Hashtag feminism is "one of the most popular forms of feminist activism and involves using hashtags (the \# symbol followed by a thematic word of phrase) to produce communities of conversation among disparate Twitter users" [1] (pp. 237).

8 Following Opie [87] (p. 367), quotations were selected using six criteria: (1) the intensity of participant's speaking voice (indicating emotional attachment/importance); (2) the contradictory moment (where participants may contradict themselves or acknowledge the contradictions of their actions); (3) emotional content or tone (indicating emotional attachment/importance and complexity of message); (4) and the extent to which the participant uses whole sentences, rather than the more usual recursive/repetitive speech patterns (which may indicate certainty and/or a strong belief). In addition to Opie's criteria, quotes were selected that (5) eloquently and/or explicitly stated things that other participants talked about less eloquently or obviously, as well as quotes that (6) help to define where boundaries are constructed or challenged (e.g., "we do $a$, but not $\left.b^{\prime \prime}\right)$, since this is a preoccupation of my research.

9 Anita Sarkeesian is a feminist media critic and media literacy video creator who has been the target of large-scale online harassment campaigns and violent threats, including death threats that forced her family to go into hiding in 2014.

10 \#WhyIStayed was a 2014 hashtag that challenged victim-blaming myths around intimate partner violence, in response to National Football League player Ray Rice's video recorded physical assault on his fiancée Janay Palmer (now Janay Rice). 
I feel like on Twitter I can actually reach people who are following certain hashtags, etc. and who are really engaged in the issues, either activists, activists, or communicators in some way.

By connecting through social media, individuals and organizations can, as one participant explained, work collaboratively to "signal-boost" (e.g., share, like) each other's content in order to build momentum in their work.

Most participants work in a combination of online and face-to-face settings, and use social media for specific goals such as generating attention and awareness to VAW. In other words, VAW prevention in social media does not replace other forms of prevention, but rather expands this work. For example, one writer and activist explains how she sees hashtag activism as a supplemental, rather than a replacement, modality of VAW prevention:

I know people disdain hashtag activism, but I hardly know anyone who only does hashtag activism. Most of the people I know do hashtag activism in addition to other activism, so I don't think people are doing it by and large and then saying, ok I don't have to pay attention to this anymore. I think that it can be really effective in terms of raising consciousness about an issue really quickly and demonstrating that a critical mass of people experience this [VAW] ... It is also really effective at generating traditional media attention, which really needs to happen.

A key first step in VAW prevention work is to achieve broad public recognition that VAW is a social problem. For participants, the notion of "raising awareness" generally appears to mean getting mainstream populations (broader audiences outside of the VAW sector) to see VAW as a social problem: to take it seriously and want to take steps to prevent it from occurring. As the participant above explained, this is also aided by traditional media attention, a theme that will be discussed further below as well as in later sections.

In some cases, participants are trying to evoke an emotional response to VAW. For example, one writer and advocate explains that they are trying to break through public apathy surrounding VAW:

I want VAW to be something people are horrified by, but it's so commonplace it doesn't even register. People are numb to it. Not everyone, but I get that feeling that as a culture we're numb. Or culturally we are outraged at the way other countries handle VAW ... for instance when the world got upset about the way India responds to rape without taking a look at it at home. It's OK to be offended at the way other people in other countries treat women but we don't take a look at ourselves. Like not looking at the high rates of violence against First Nations women as part of a socioeconomic issue, which of course it is.

Several participants noted that social media facilitates raising awareness by enabling survivors to share stories about their victimization (similar to \#MeToo), as those with experiential knowledge are effective at connecting on an emotional level. For example, as one writer and advocate explains below:

I'm a huge believer in storytelling and the power of free media. So from that perspective, I think that the Internet is transformative in the fight against gender-based violence. Because, for the first time ever, women can step out of the isolation that they've always been subject to, and share their stories ... I think [this] can really engage people more empathetically to understand the scope of what we're talking about.

Increased attention to VAW on social media and traditional news media is seen as an indicator of success for some. For example, one advocate and educator who has worked in VAW prevention for many years remarks that conversations around VAW are happening more frequently in her local media in the past year:

I will always think of that big moment when [a local newspaper] had a cover page about rape culture and had the word rape culture. And it wasn't like "does it exist?" It was "what do we do about it?" ... You know, [the story] lacked nuance and they quoted MRAs [Men's Rights Activists] inside and 
all kind of other things, but it was the mainstream. The word rape culture in [my city] has hit the mainstream. Good, bad, or otherwise, when I say it now, people still get very defensive, and I still think it's a really extreme word for a lot of people, but for me that was like, wow ... So I think social media has for better or for worse allowed us to significantly speed up where we've come. I mean, speaking only on the issue of sexual violence, but I think we have made progress.

Other participants note that, despite the value of starting conversations to raise awareness, there is a need to link these narratives to broader societal and structural change. For example, one communications director explains that "thinking about the stories we tell in order to advance the policies we want is a really crucial piece of prevention". The idea, then, is that conversations about VAW should be driven with a consideration of broader VAW movement goals in terms of communityand societal-level change.

\subsection{Narrative Shifts to Change Societal Norms}

Preventing VAW requires changing attitudes, beliefs, and social norms that tolerate, excuse, and encourage VAW, a historically challenging area of prevention [27]. As highlighted earlier, harmful narratives around VAW include an absence of broader context (e.g., VAW terminology, research knowledge), as well as misogyny and reproduction of rape myths and other ingrained (false) beliefs about VAW (e.g., women frequently lie about sexual assault; violence is gender-neutral; women stay because they like the abuse). Participants explain that public education efforts to promote understanding VAW as a social problem is often met with pushback from anti-feminist groups such as MRA's, as well as general public apathy or skepticism. For example, one blogger and advocate describes her use of social media around VAW in this way:

The first thing is just raising awareness. And particularly trying to cut through some of the MRA stuff that goes around about the "what about the men" kind of stuff. So trying to say, this isn't it, we're not trying to take away that it sucks about violence committed against anybody. The raising awareness about yes, this is still an issue, yes this is everybody's issue, yes gender is still a factor. So I think that's one really key thing.

Prevention work in social media highlights the gendered nature of intimate partner violence and sexual violence and specifically targets harmful myths and stereotypes about VAW. As one participant remarks, "I think the opportunities available in dialogue are significant for changing social norms. And social media for me is the natural place to change social norms".

The speed and reach of social media information-sharing means that it has the potential to disseminate myths around VAW, but also makes it a powerful tool for prevention work. One communications professional explains that their work involves "bringing communications strategy, big-picture narrative framing, to the work that is in the field." When describing how they viewed changing narratives as a key part of the role of social media in VAW prevention, they explain the following:

I do [see it] in two ways. One, is I think social media, because it moves so fast. It's both potentially powerful and potentially dangerous because it can really, you can perpetrate a lot of myths very quickly ... But I think that social media is particularly important because of the speed and the momentum, but also the reach ... changing those really fundamental narratives around sexuality of women is difficult, because a lot of why women have been subjugated over time has always been fear of female sexuality. And I think that that's really hard for a lot of people to grasp: that something that's about violence against women, you know, violence around sexuality, is actually rooted in fear of sexual power. That's complex stuff, and it's really hard to tweet about it.

Individualized, simplistic explanations that focus on victim behaviors (e.g., "she was drunk, what did she think would happen?") are easier to digest and are deeply engrained in societal understandings of this violence [34]. As we see from this quote, one of the challenges of conversations 
in social media is to effectively discuss community- and societal-level risk factors (e.g., gender socialization; norms around women's sexuality). This complexity and nuance is particularly difficult to inject in a space where user attention spans and content space (e.g., character limits on Twitter) may be restricted.

As part of raising awareness, challenging behaviors that support and foster rape culture is a priority for VAW prevention work in social media. For example, one public educator and advocate explains the importance of education around abusive behaviors and bystander intervention:

The primary focus of our outreach online is just the awareness, the education component ... that public education component as far as educating people about rape culture, and making them understand what comments they made that are actually reinforcing that, or the behaviour that they have witnessed or experienced or perhaps even committed themselves, that it's actually unacceptable. That kind of component has to take the lead online.

While some participants work at organizations that provide front line support, for the most part, participants are not using social media to target individuals for one-on-one support. Rather, social media work is primarily geared at broader publics and potential perpetrators. For example, one advocate notes:

You're definitely right in recognizing that much of our counselling and outreach type stuff directly to women is done in person ... we have different approaches, and most of it is done in person when it comes to the direct contact to the women in crisis. More of our online stuff is directed at the public per se, when it comes to prevention from that angle as far as how to not be an abuser, that angle tends to be a big focus online.

By educating individuals in a publicly accessible and sharable context, participants are trying to change both attitudes and beliefs (individual-level risk factors) in the short term, and social norms (community- and societal-level risk factors) in the long term.

Interventions can also be used reflexively to highlight problematic practices within VAW prevention work. For example, one activist and researcher explains she will use social media to call out victim-blaming messaging within her own community, as well as the media more broadly:

A lot of the campaigns around violence are still so shitty, they're still really focused on women's behaviour. And even with [our organization] I think a lot of the, I don't want to say older, but I'm going to, are still- they really internalize those messages of "women, you need to stay safe" [and so forth]. And when I see that, I mean it makes me very angry, and so I try to correct it and say, you know this is really problematic. But there's still not widespread agreement on what even needs to be done to stop violence against women, let alone how we need the media to better respond. And I am thankful for being able to talk back to what's out there, because I'm not the kind of person who logs on to [a news site] and puts comments, that's not me. But yeah, I will respond to something I see from the media that's posted, or something within [my community] that I feel is a problem.

In this case, social media allows for a "talk-back" mechanism to voice dissent and highlight harmful narratives, and to push the broader movement forward. VAW prevention work has moved away from responsibilization narratives [88] that focus on victim behavior ("don't get assaulted") towards accountability narratives that focus on perpetrators' behavior ("don't assault"). This can be seen in various participants' comments when they talk about their goals related to prevention. For example, as one advocate explains, victim-blaming narratives (a central feature of rape culture) are a core target:

We've finally made that transition from talking to young women about-it was a form of victim-blaming when we kept telling girls "don't dress this way" or "don't walk alone at night" or "carry this with you". Yeah, we're trying to do harm reduction here, but at the same time it's so important-we've finally moved away from that. 
Victim-blaming narratives from individuals and organizations (e.g., politicians, police, college campus representatives, media outlets), for example, are precisely the situations where VAW prevention workers are aiming to intervene and reframe. The use of social media to critique messaging is particularly important for powerful institutions like news media, which play an important role in public education about VAW, reproducing social norms around VAW, and shaping policy debates $[45,89]$.

\subsection{Mobilization around High-Profile News Stories}

To understand the importance of intervening in VAW news stories, we can consider participants' (many) frustrations with mainstream media. As discussed earlier, there has historically been much feminist activist and academic critique of news reporting of VAW as failing to convey context, nuance, and complexity around VAW. Many participants have similar concerns, and several express frustrations over lack of control of the message. One activist, who has extensive experience as a news source in mainstream media, describes this lack of control:

I'm kind of the dog and pony, the right poster girl. And they ask me for comments constantly. And I'll respond of course, that's my job. But I'm not in charge of what's going on, I'm responding, reacting. And you must speak in sound bites. And you must be effective. And you really need to understand that what you're saying, and the ways that you're saying it, can change the tone of the story, because someone else is translating that for you. Or they're translating it to a certain party or public, who then hear it in yet different ways.

Additionally, as several participants explain, journalists often have limited understanding of VAW, and can themselves perpetrate harm through representation. For example, this same participant explains:

Journalists don't understand the nature of the crime. And they'll tell you that right away ... it's the first, second, third, and fourth case that the journalist who has just graduated is sent out on. So they are using their own biases, their own language, and their own misunderstandings of the crime, and repeating and solidifying myths and stereotypes.

Several participants view the news media as an arena that frequently counteracts VAW prevention objectives; as such, they feel it is important to intervene in these online discussions. Social media enables this to be done publicly; for example, tweeting at the news organization that published a victim-blaming headline [90]. This provides the feedback to the news organization, while also allowing other online bystanders to see the interaction and participate if so inclined.

Mobilization around news stories, particularly high-profile events, aims to bring a VAW lens to ongoing conversations surrounding current events and trending topics. This provides sociological context to shift understanding from individual level explanations (e.g., the perpetrator was a psychopath) to larger social forces contribute to the root causes of violence (e.g., the role of misogyny). For example, one advocate and public educator explains that social media is an important tool to provide ("force") missing feminist analysis of current news stories:

When a hashtag is covered in the mainstream media, when \#SolidarityIsForWhiteWomen ${ }^{11}$ is a story, when \#YesAllWomen- with that analysis of what happened in California, ${ }^{12}$ that analysis would not

11 An AlJazeera [91] blog entry explains that the hashtag \#SolidarityIsForWhiteWomen "was originally coined by blogger Mikki Kendall during a Twitter debate about Hugo Schwyzer, an American academic and self-described male feminist. Schwyzer has been accused of harassing non-white female bloggers and recently wrote that his critics drove him offline." The hashtag gained worldwide attention as Twitter users criticised the exclusion of nonwhite women from mainstream feminism.

12 \#YesAllWomen was started as a response to the case of Elliot Rodgers who killed six people in Santa Barbara, California before taking his own life. Prior to the killings, Rodgers had posted a (now removed) YouTube video with a manifesto "promising revenge on all the women who had rejected him" [92] (para. 1). As Feeney [92] (para. 4) explains, "Rodgers comments inspired an online conversation ... around the \#YesAllWomen hashtag to criticize the way society teaches men to feel entitled to women at the expense of their health, safety, and in Rodger's case, lives." 
have existed without social media. I firmly believe that people on social media forcing them to talk about misogyny is what made that part of the conversation.

As this quote suggests, in addition to producing news stories about incidents of VAW, mainstream media will cover stories trending on social media. Here, the mobilization around the news event (rather than the original event) becomes the news story. In this vein, several participants pointed to the example of \#BeenRapedNeverReported ${ }^{13}$, which received tens of millions of tweets and promoted the narrative that whether a survivor reports a sexual assault to police, and/or how long it takes them to do so, should not determine if we believe them, and that there are many reasons why survivors do not report sexual assaults (initially or ever). In these cases, social media (specifically, Twitter) reaches a sort of tipping point where hashtags such as \#WhyIStayed or \#IBelieveLucy (other campaigns that participants highlighted) begin to trend in response to inadequate social responses to VAW. In these cases, these hashtags challenged victim-blaming myths in response to two high profile events in 2014: (1) National Football League player Ray Rice's video recorded physical assault on his fiancée Janay Palmer, and (2) Lucy DeCoutere coming forward as one of the first survivors alleging sexual violence from former Canadian Broadcasting Company radio host Jian Ghomeshi.

In these scenarios, rather than the news media reporting on individual cases of violence, they are reporting on the social response to violence. As participants note, these hashtag conversations are visible, sharable, and searchable, enabling journalists to quote directly from this digital record, and other interested stakeholders to consume this content asynchronously.

\subsection{Challenges}

Conversations in social media gain the attention of those who may not normally pay attention to VAW. While new views and voices are positive in terms of expanding audiences and public education, they also present significant challenges related to 1) resources and 2) abuse and harassment.

For many individuals juggling heavy workloads (often in resource-strapped non-profit roles), the pace of conversation in social media is a challenge. Here, there is a difference between how organization and individuals use social media, where individuals (self-employed, freelance, and/or conducting unpaid labor online) can jump into these debates more readily. Participants working in an organizational role (e.g., using an NGO Twitter account) recognize this opportunity, but they have limited capacity to undertake the rapid response/engagement that is required to participate in that conversation. For example, one non-profit director explains that, given resource considerations, there is a choice to be made in order to have their message heard:

People don't realize that that's the commitment they need to make to be able to respond and be timely, [otherwise] you lose the message. So I think the struggle for [our organization] is that I'm the only full time paid employee... we don't have the resources to be as active as we can, so at times we have to choose. So it's kind of some competing things, so you just react as fast as you can.

The need to operate at the pace of socially-mediated news and conversation raises questions in terms of where to focus online work. This participant goes on to explain that, within social media, online comments sections place a burden of responsibility on their organization, and are one of the potentially negative outcomes of engaging wider audiences in conversations about VAW. As she explains, responding to trolling and/or negative comments is a particular challenge when it comes to joining conversations:

It's hard to negotiate, because you want to have a voice, but having a voice requires a person to have that voice ... there are these small windows that if you had a team of people doing it, you are going

13 \#BeenRapedNeverReported was co-created by Toronto Star reporter Antonia Zerbisias and Montreal Gazette justice reporter Sue Montgomery, who decided to publicly share their own experiences of assault on Twitter on October 30, 2014. There were tens of millions of tweets, retweets and replies and national and international media outlets reported on it [93]. 
make a great change I think. Because people are seeing that, and people are reading those comments but the fact of the matter is that really the only choice sometimes that we're given because of low staff and the high amount of time that takes, is not to answer [trolls and negative comments].

While social media offers expanded opportunity for VAW prevention, without the addition of resources and social media expertise, it may be a lost opportunity or additional drain on already resource-strapped organizations. Although many individuals are taking on social media work as personal (and unpaid) activism around VAW prevention, they do so oftentimes at great cost both in terms of time and energy.

These challenges are further exacerbated by experiences of backlash, harassment, and abuse. Several participants described experiencing online harassment and abuse as a result of their VAW prevention work in social media. However, these experiences are not uniform. Some participants talk about being the target of rape threats or online hate-based campaigns because of their work, others talk about their fears of receiving such abuse. Still others speak more generally about "trolls", "incivility", "vitriol", and so forth. For example, one writer and activist detailed her experiences as follows:

The worst, the two worst incidents I ever had, one was after I blocked comments on YouTube, someone [found me online] and basically said, "You're a liar, and I hope that someone kills you, I hope that it will be me". So I had to call the police about that, which was fun ... And then another time, someone on Twitter said, "someone on Facebook is using your picture, and you should really get it taken down." And I found that someone had used my headshot as the front picture for this [harassment page] ... when I found my picture, there were 600 comments, about how I should head butt a gun, how someone should rape me with a watermelon, all these rape threats, how no one would have sex with me because I'm so ugly and I'm a pig, and I'm fat ... And I was very close to just quitting, because it was really awful.

Another advocate and educator explains the effects of this harassment, and also illustrates that harassment is not limited to online abuse:

There's definitely stuff that has been threatening-I mean someone, somehow got my number and I got all these threatening phone calls last week. But I think to me it's more-it's just exhausting. It's more exhausting... I think the threatening is maybe 5 percent of it and the rest is just like really, fuck off.

Some participants have lobbied for social media platforms to take an active role in preventing violence enabled by their sites. For example, one advocate explains that it is important that social media companies take this abuse seriously because "[online abuse] curtails a lot of activism, and their-Facebook and Twitter's-official definitions of what is abuse and what is not is pretty disheartening". Another participant, a writer and activist, details the misogynistic nature of these threats and argues that social media companies have a responsibility to be active bystanders and to explore online violence as a threat to women's free speech:

I started really paying attention to the nature of the harassment and the threats. And you know, a lot of it was just kind of intrinsically misogynistic language: "bitch" and "cunt" and "slut". And critiques of my ideas or my work, often in those contexts just came down, as they often do, to violence, like hanging or rape or throttling ... I want these companies to understand that women's perceptions of all of these things- safety, harm, threat, free speech- are legitimate, and that they (the companies) need to take those into consideration... If you want to liberate speech, then you have to remove the violence that women are experiencing in life.

Challenges for discussing gender in the public sphere are well-documented $[14,15,94]$ and gender is a key factor in experiences of abuse and harassment on the internet [95]. Increasingly, online harassment is recognized as a form of VAW and a gendered silencing strategy [95-97]. Given the high burnout rates among service providers, advocates, and activists, it is important to take the depletive effects of dealing with harassment (and/or fears of harassment) seriously. Being forced out of social media, or even just certain social media sites, hinders prevention efforts. 
As with historical efforts to mobilize against domestic violence in the home and sexual harassment in the workplace [6,8], identifying and responding to VAW online has some time to catch on. As one public educator explains, public recognition of the problem is a critical first step:

In terms of the sort of cycle of raising awareness about an issue and getting people equipped, I think with sexual violence we're at that bystander intervention and tactical [stage], like practical "this is what we can do to stop it". Whereas with online violence, we're still trying to convince people that it's a thing.

As this work continues, it is important to value and support these efforts and to prioritize the well-being of those doing online work [1]. In this vein, it is helpful to conceptualize VAW prevention work in social media as bystander intervention.

\section{Discussion and Conclusions}

Social media is an important space for many pre-social media violence prevention strategies such as raising awareness of VAW as a social problem and challenging sexist and misogynistic attitudes. In this study, we see how these strategies shift to and expand in Facebook and Twitter to capitalize on opportunities to shape conversations about VAW, such as through mobilization around high-profile stories and trending hashtags. What is perhaps unique to social media, beyond the speed and the reach of conversations, is that these stories, critiques, and commentaries are not happening in a private, face-to-face capacity, but are visible and shareable to an audience that could range from dozens to millions. Because of the potential audience, then, there is an increased need to intervene in these social situations to not let myths and misrepresentations stand unchallenged, particularly when these come from powerful community figures and institutions such as police, political figures, and media. In this way, VAW prevention workers are "using culture to change culture" as one participant explained. This is in line with more recent prevention approaches aiming to transform social norms, relations, and systems that support VAW [30]. This shift recognizes that communities, organizations, and institutions are also complicit in VAW and thus have a role to play in ending this violence.

Because of this complicity, it is important to unpack how bystander intervention can take place beyond individual interventions and target community and societal risk factors such as social norms supportive of VAW, sensational or victim-blaming media portrayals, or myths surrounding male superiority and sexual entitlement, as examples. Perhaps because bystander intervention is generally presented as something that happens in physical, face-to-face settings, most participants do not describe their online work as bystander intervention. Instead, they speak about public education more broadly, about working to change attitudes, beliefs, and social norms, or of teaching others to support survivors and intervene in situations that support or encourage VAW. However, understanding this work as bystander intervention is valuable for several reasons. First, it may build stronger networks. Specifically, it can build common ground between socio-political activist networks (e.g., feminist activists) and those working in education and social psychology that may be more focused on individuals and geographically-bound communities (e.g., bystander intervention programs on college campuses). Second, it may provide legitimacy and therefore, resources. This legitimacy is important because it could create opportunities for formal, funded programs and evaluation. Bystander intervention programs such as the Green Dot [98] and Bringing In The Bystander [99] are funded, curriculum-based programs. Currently, a great deal of social media work is unfunded (or indirectly funded) and informal practice. Additionally, much social media activism and advocacy has been criticized for being "slacktivism" [100]. Even if this association is not explicitly used to refer to VAW prevention work, there may be hesitation to provide resources to social media work if it is viewed as competing with face-to-face work.

A third reason to link VAW prevention in social media and bystander intervention, also related to legitimacy, is to acknowledge it as labor (in terms of time and emotional and financial resources). If social media work is creating additional strain on personal and organizational resources (which 
many participants suggest is the case), it is important that we develop a research trail in this area. Additionally, participants' experiences of online violence, and emerging scholarship conceptualizing and documenting online VAW [97,101,102], point to a potential need to develop anti-harassment interventions when this form of labor takes place. Stemming from this, and as a fourth and final point, understanding social media work as a space for bystander intervention means that stakeholders can further consider how to design online spaces in ways that encourage reactive and proactive bystander behaviors. Here, drawing from interdisciplinary research is particularly important, and we cannot simply transfer what we know about offline behavior online. For example, research from computer science and psychology suggests that likelihood of online bystander intervention may be affected by perceptions of surveillance and risk in chat rooms [103]. Additionally, contrary to notions of diffusion of responsibility, people may be more likely to intervene in situations where there are other people present and when they are aware they are being monitored by technology such as security cameras [104]. By treating social media as a legitimate space for bystander intervention, we may be able to shift community responses and social norms in timely, personalized, and low-risk ways, while simultaneously supporting survivors and minimizing resource drain and abuse directed at VAW prevention workers.

Given the persistent and pervasive existence of VAW, prevention approaches should be creative and adaptable to shifting media technologies and changing cultural norms around communication. Scholars such as Banyard [67] raise the need for fluid approaches to bystander intervention when exploring how best to target prevention efforts. As Banyard [67] (p. 226) explains, a social-ecological model is particularly valuable in this capacity:

Ecological theory also reminds us that processes like bystander intervention are not static or linear and likely change over time with shifts in community experiences, attitudes, or policies. This next level of analysis is critical, as it helps us think more about the larger context around individual bystanders. Influential variables at these broader levels may become leverage points for change themselves.

By using social media to intervene in conversations and shape narratives surrounding VAW, participants translate typically offline bystander intervention strategies online into arguably lower-risk contexts (where physical victimization is not immediate, though we should not downplay the harmful effects of emotional and psychological violence both in and out of social media). VAW prevention workers are not only promoting and/or teaching active bystander intervention as something that should take place in face-to-face public settings (reactive and proactive bystander behaviors), but are engaging in additional proactive bystander behaviors by providing feminist analysis and critique and promoting anti-violence social norms. These efforts are grounded in the understanding that (1) social media content (news coverage; online conversations) plays a role in shaping individual attitudes and beliefs that may support (or resist) VAW; and that (2) inaccurate, sensational, stereotypical, and victim-blaming content is itself a form of harm requiring bystander intervention. Expanding our understanding of bystander intervention to include such work allows us to value this work and also acknowledge the role of news media organizations and social media platforms as potentially complicit community members.

Of course, VAW prevention workers represent a more-easily mobilized population in that they are already committed to the goal of ending VAW. To what extent these strategies and ideals are transferable to broader publics outside this sector is an important area for further study to expand knowledge of online bystander intervention efforts. This expansion also requires further consideration of the challenges and risks of online VAW prevention work. While these online situations may be considered lower-risk, many individuals doing VAW prevention work experience challenges related to resources and are themselves targets of gendered and sexualized violence as a result of their public work. These findings support research highlighting the frequent abuse experienced by feminists online and the need to conceptualize this abuse as a form of VAW [105], as well as the need to value and protect bystanders in prevention work [67]. Rather than creating silos of offline and online work, 
further efforts are needed to support and advance this work as part of larger goals to strengthen community and social responses to violence.

Funding: This research was funded by the Social Sciences and Humanities Research Council of Canada grant number [767-2010-1509].

Acknowledgments: Thank you to Myrna Dawson, Aaron Doyle, and the editors and anonymous reviewers for their guidance and feedback on this article.

Conflicts of Interest: The author declare no conflict of interest.

\section{References}

1. Mendes, K.; Ringrose, J.; Keller, J. \#MeToo and the promise and pitfalls of challenging rape culture through digital feminist activism. Eur. J. Women Stud. 2018, 25, 236-246. [CrossRef]

2. Fileborn, B.; Loney-Howes, R.E.; Hindes, S. \#MeToo Has Changed the Media Landscape, but in Australia There Is Still Much to Be Done. 2019. Available online: https://theconversation.com/metoo-has-changed-themedia-landscape-but-in-australia-there-is-still-much-to-be-done-111612 (accessed on 15 March 2019).

3. Brunner, E.; Partlow-Lefevre, S. \#MeToo as Networked Collective: Examining Consciousness-Raising on Wild Public Networks. Available online: https://www.tandfonline.com/doi/abs/10.1080/14791420.2020.1750043 (accessed on 12 July 2020).

4. ElSherief, M.; Belding, E.M.; Nguyen, D. \# NotOkay: Understanding Gender-Based Violence in Social Media. In Proceedings of the Eleventh International AAAI Conference on Web and Social Media, Montréal, QC, Canada, 15-18 May 2017.

5. Smart, C.; Smart, B. Smart for rape: Reality and myth in press reporting. In Women, Sexuality and Social Control; Smart, C., Smart, B., Eds.; Routledge: Abingdon, UK, 1978; pp. 87-104.

6. Tierney, K.J. The battered women movement and the creation of the wife beating problem. Soc. Probl. 1982, 29, 207-220. [CrossRef]

7. Cancian, F.; Ross, B. Mass media and the women's movement: 1900-1977. J. Appl. Behav. Sci. 1981, 17, 9-26. [CrossRef]

8. Van Zoonen, E.A. The Women's Movement and the Media: Constructing a Public Identity. Eur. J. Commun. 1992, 7, 453-476. [CrossRef]

9. Mendes, K. Reporting the women's movement: News coverage of second-wave feminism in UK and US newspapers, 1968-1982. Fem. Media Stud. 2011, 11, 483-498. [CrossRef]

10. Heise, L.L. Violence against women: An integrated, ecological framework. Violence Against Women 1998, 4, 262-290. [CrossRef]

11. Dahlberg, L.L.; Krug, E.G. Violence a global public health problem. Ciênc. Saúde Coletiva 2006, 11, 277-292. [CrossRef]

12. McMahon, S.; Banyard, V.L. When Can I help? A Conceptual Framework for the Prevention of Sexual Violence Through Bystander Intervention. Trauma Violence Abus. 2011, 13, 3-14. [CrossRef]

13. Jewkes, R.; Purna, S.; Garcia-Moreno, C. Sexual Violence. In World Report on Violence and Health; Krug, E., Dahlberg, L., Mercy, J., Zwi, A., Lozano, R., Eds.; World Health Organization: Geneva, Switzerland, 2002; pp. 147-182.

14. Grauerholz, L.; Baker-Sperry, L. Feminist Research in the Public Domain. Gend. Soc. 2007, 21, 272-294. [CrossRef]

15. Sprague, J.; Laube, H. Institutional Barriers to Doing Public Sociology: Experiences of Feminists in the Academy. Am. Sociol. 2009, 40, 249-271. [CrossRef]

16. The World Health Organization. Understanding and Addressing Violence against Women. 2012. Available online: https://apps.who.int/iris/bitstream/handle/10665/77432/WHO_RHR_12.36_eng.pdf;jsessionid= FAAA311FDAA60D6408466198F743070F? sequence $=1$ (accessed on 17 April 2020).

17. Dobash, R.E.; Cavanagh, K.; Lewis, R.; Dobash, R.P. Not an Ordinary Killer-Just an Ordinary Guy. Violence Against Women 2004, 10, 577-605. [CrossRef]

18. Dawson, M. Intimacy and violence: Exploring the role of victim-defendant relationship in criminal law. J. Crim. Law Criminol. 2006, 96, 1417-1449. 
19. Rasche, C.E. Early Models for Contemporary Thought on Domestic Violence and Women Who Kill Their Mates. Women Crim. Justice 1990, 1, 31-53. [CrossRef]

20. Sev'er, A.; Dawson, M.; Johnson, H. Guest editors' introduction: Lethal and nonlethal violence against women by intimate partners: Trends and prospects in the United States, the United Kingdom, and Canada. Violence Against Women 2004, 10, 563-576.

21. Garcia, L.; Soria, C.; Hurwitz, E.L. Homicides and Intimate Partner Violence. Trauma Violence Abus. 2007, 8, 370-383. [CrossRef] [PubMed]

22. Crenshaw, K. Mapping the Margins: Intersectionality, Identity Politics, and Violence against Women of Color. Stanf. Law Rev. 1991, 43, 1241. [CrossRef]

23. Collins, P.H. Healing Identities: Black Feminist Thought and the Politics of Groups (review). Hypatia 2000, 20, 227-230. [CrossRef]

24. Potter, H. An Argument for Black Feminist Criminology. Fem. Criminol. 2006, 1, 106-124. [CrossRef]

25. hooks, bell. Ain't I A Woman: Black Women and Feminism; South End Press: Boston, MA, USA, 2007.

26. Bronfenbrenner, U. The Ecology of Human Development: Experiments by Nature and Design; Harvard University Press: Cambridge, MA, USA, 2009.

27. Johnson, H.L.; Dawson, M. Violence Against Women in Canada: Research and Policy Perspectives; Oxford University Press: Oxford, UK, 2011.

28. World Health Organization/London School of Hygiene and Tropical Medicine. Preventing Intimate Partner and Sexual Violence Against Women: Taking Action and Generating Evidence; World Health Organization: Geneva, Switzerland, 2010. Available online: https://www.who.int/violence_injury_prevention/publications/violence/ 9789241564007_eng.pdf?ua=1 (accessed on 17 April 2020).

29. Dewing, M. Social Media: Who Uses Them; Library of Parliament: Ottawa, ON, Canada, 2012.

30. Jewkes, R.; Flood, M.; Lang, J. From work with men and boys to changes of social norms and reduction of inequities in gender relations: A conceptual shift in prevention of violence against women and girls. Lancet 2015, 385, 1580-1589. [CrossRef]

31. Ellsberg, M.; Arango, D.J.; Morton, M.; Gennari, F.; Kiplesund, S.; Contreras, M.; Watts, C. Prevention of violence against women and girls: What does the evidence say? Lancet 2015, 385, 1555-1566. [CrossRef]

32. Berns, N. Framing the Victim: Domestic Violence, Media, and Social Problems; Aldine DeGruyter: New York, NY, USA, 2004.

33. Fairbairn, J.; Dawson, M. Canadian News Coverage of Intimate Partner Homicide. Fem. Criminol. 2013, 8, 147-176. [CrossRef]

34. Benedict, H. Virgin or Vamp: How the Press Covers Sex Crimes; Oxford University Press on Demand: New York, NY, USA, 1993.

35. Moore, S.E.H. Cautionary tales: Drug-facilitated sexual assault in the British media. Crime Media Cult. Int. J. 2009, 5, 305-320. [CrossRef]

36. O'Hara, S. Monsters, playboys, virgins and whores: Rape myths in the news media's coverage of sexual violence. Lang. Lit. 2012, 21, 247-259. [CrossRef]

37. Bullock, C.F.; Cubert, J. Coverage of Domestic Violence Fatalities by Newspapers in Washington State. J. Interpers. Violence 2002, 17, 475-499. [CrossRef]

38. Carlyle, K.E.; Slater, M.D.; Chakroff, J.L. Newspaper Coverage of Intimate Partner Violence: Skewing Representations of Risk. J. Commun. 2008, 58, 168-186. [CrossRef]

39. Ryan, C.; Anastario, M.; DaCunha, A. Changing coverage of domestic violence murders A longitudinal experiment in participatory communication. J. Interpers. Violence 2006, 21, 209-228. [CrossRef]

40. Bullock, C.F. Framing Domestic Violence Fatalities: Coverage by Utah Newspapers. Women Stud. Commun. 2007, 30, 34-63. [CrossRef]

41. Dobash, R.E.; Dobash, R.P.; Cavanagh, K. Out of the blue: Men who murder an intimate partner. Fem. Criminol. 2009, 4, 194-225. [CrossRef]

42. Campbell, J.C. If I can't have you, no one can: Power and control in homicide of female partners. In Femicide: The Politics of Woman Killing; Radford, J., Russell, D., Eds.; Twayne Publishers: Woodbridge, CT, USA, 1992; pp. 99-113.

43. Howe, A. The War Against Women. Violence Against Women 1997, 3, 59-75. [CrossRef]

44. Meyers, M. News Coverage of Violence against Women: Engendering Blame; Sage Publications: Thousand Oaks, CA, USA, 1996. 
45. Welch, M.; Fenwick, M.; Roberts, M. Primary Definitions of Crime and Moral Panic: A Content Analysis of Experts' Quotes in Feature Newspaper Articles on Crime. J. Res. Crime Delinq. 1997, 34, 474-494. [CrossRef]

46. Jiwani, Y.; Young, M.L. Missing and Murdered Women: Reproducing Marginality in News Discourse. Can. J. Commun. 2006, 31, 895-917. [CrossRef]

47. Carlyle, K.E.; Orr, C.; Savage, M.W.; Babin, E.A. News Coverage of Intimate Partner Violence: Impact on Prosocial Responses. Media Psychol. 2014, 17, 451-471. [CrossRef]

48. Moral, P.G.-D. Representation as a Technology of Violence: On the Representation of the Murders and Disappearances of Aboriginal Women in Canada and Women in Ciudad Juarez. Can. J. Lat. Am. Caribb. Stud. 2011, 36, 33-62. [CrossRef]

49. Canadian Resource Centre for Victims of Crime. Victims and the Media. Available online: https://crcvc.ca/ publications/media-guide/victims-and-media/ (accessed on 22 May 2020).

50. Chicago Taskforce on Violence Against Girls and Young Women. Reporting On Rape and Sexual Violence: A Media Toolkit for Local and National Journalists to Better Media Coverage. 2012. Available online: http: //www.chitaskforce.org/wp/wp-content/uploads/2012/10/Chicago-Taskforce-Media-Toolkit.pdf (accessed on 1 February 2015).

51. Femifesto. Media Toolkit. 2013. Available online: http://femifesto.ca/home/media-toolkit/ (accessed on 1 February 2015).

52. Minnesota Coalition Against Sexual Assault. Reporting on Sexual Violence: A Guide for Journalists. 2013. Available online: http://www.mncasa.org/index_451_3523309454.pdf (accessed on 1 February 2015).

53. Rhode Island Coalition Against Domestic Violence. (n.d.) Telling the Full Story: An Online Guide for Journalists Covering Domestic Violence. Available online: http://dvonlineguide.org/en/ (accessed on 1 February 2015).

54. Bissler, D.; Conners, J. The Harms of Crime Media: Essays on the Perpetuation of Racism, Sexism and Class Stereotypes; McFarland Co., Inc.: Jefferson, NC, USA, 2012.

55. International Women's Media Foundation (IWMF). Global Report on the Status of Women in the News Media. 2011. Available online: http://iwmf.org/pdfs/IWMF-Global-Report.pdf (accessed on 15 March 2020).

56. Padovani, C. Speaking Truth to Power about Gender and Communication: International and Regional Policy Developments Towards Beijing+20. Fem. Media Stud. 2014, 14, 318-322. [CrossRef]

57. Kingston, M.L. What can feminism learn from new media? Commun. Crit. Cult. Stud. 2014, 11, $293-297$. [CrossRef]

58. Lokot, T. \#IAmNotAfraidToSayIt: Stories of sexual violence as everyday political speech on Facebook. Inf. Commun. Soc. 2018, 21, 802-817. [CrossRef]

59. Korn, J.U.; Kneese, T. Guest Editors' Introduction: Feminist Approaches to Social Media Research: History, Activism, and Values. Fem. Media Stud. 2015, 15, 707-710. [CrossRef]

60. Zaleski, K.L.; Gundersen, K.K.; Baes, J.; Estupinian, E.; Vergara, A. Exploring rape culture in social media forums. Comput. Hum. Behav. 2016, 63, 922-927. [CrossRef]

61. Garcia, C.K.; Vemuri, A. Girls and Young Women Resisting Rape Culture through YouTube Videos. Girlhood Stud. 2017, 10, 26-44. [CrossRef]

62. Powell, A. Configuring Consent: Emerging Technologies, Unauthorized Sexual Images and Sexual Assault. Aust. N. Z. J. Criminol. 2010, 43, 76-90. [CrossRef]

63. Salter, M. Justice and revenge in online counter-publics: Emerging responses to sexual violence in the age of social media. Crime Media Cult. Int. J. 2013, 9, 225-242. [CrossRef]

64. Dodge, A. Digitizing rape culture: Online sexual violence and the power of the digital photograph. Crime Media Cult. Int. J. 2015, 12, 65-82. [CrossRef]

65. Potter, S.J.; Moynihan, M.M.; Stapleton, J.G.; Banyard, V.L. Empowering bystanders to prevent campus violence against women a preliminary evaluation of a poster campaign. Violence Against Women 2009, 15, 106-121. [CrossRef] [PubMed]

66. Minow, M. Upstanders, whistle-blowers, and rescuers. The Bystander Dilemma: The Holocaust, War Crimes, and Sexual Assaul. Utah Law Rev. 2017, 2017, 815-837.

67. Banyard, V.L. Who will help prevent sexual violence: Creating an ecological model of bystander intervention. Psychol. Violence 2011, 1, 216-229. [CrossRef]

68. Hayes, B.E. Bystander Intervention to Abusive Behavior on Social Networking Websites. Violence Against Women 2018, 25, 463-484. [CrossRef] 
69. Naab, T.K.; Kalch, A.; Meitz, T.G.K. Flagging uncivil user comments: Effects of intervention information, type of victim, and response comments on bystander behavior. New Media Soc. 2016, 20, 777-795. [CrossRef]

70. Banyard, V.L.; Moynihan, M.M.; Plante, E.G. Sexual violence prevention through bystander education: An experimental evaluation. J. Community Psychol. 2007, 35, 463-481. [CrossRef]

71. Cook-Craig, P. Youth Sexual Violence Prevention. National Resource Centre on Violence Against Women. 2012. Available online: http://www.vawnet.org (accessed on 15 June 2016).

72. Bivens, R. Digital Currents: How Technology and the Public Are Shaping TV News; University of Toronto Press: Toronto, ON, Canada, 2014.

73. Rentschler, C. \#Safetytipsforladies: Feminist Twitter Takedowns of Victim Blaming. Fem. Media Stud. 2015, 15, 353-356. [CrossRef]

74. Rentschler, C.A. Bystander intervention, feminist hashtag activism, and the anti-carceral politics of care. Fem. Media Stud. 2017, 17, 565-584. [CrossRef]

75. McPhail, B.A.; Busch, N.B.; Kulkarni, S.; Rice, G. An Integrative Feminist Model. Violence Against Women 2007, 13, 817-841. [CrossRef] [PubMed]

76. Bertaux, D. From the life-history approach to the transformation of sociological practice. In Biography and Society: The Life History Approach in the Social Sciences; Bertaux, D., Ed.; Sage: London, UK, 1981; pp. $29-45$.

77. Marshall, B.; Cardon, P.; Poddar, A.; Fontenot, R. Does Sample Size Matter in Qualitative Research? A Review of Qualitative Interviews in is Research. J. Comput. Inf. Syst. 2013, 54, 11-22. [CrossRef]

78. Charmaz, K. Grounded Theory: Methodology and Theory Construction. In International Encyclopedia of the Social Behavioral Sciences; Elsevier BV: Amsterdam, The Netherlands, 2015; pp. 402-407.

79. Bowen, G.A. Naturalistic inquiry and the saturation concept: A research note. Qual. Res. 2008, 8, 137-152. [CrossRef]

80. Fairbairn, J. Ecologies of Change: Violence against Women Prevention, Feminist Public Sociology, and Social Media; 2015. Available online: https:/curve.carleton.ca/system/files/ etd/d0d9e7fa-cc2f-480d-a3cd-ae0911b3981c/etd_pdf/70773da2a4eb7936581d0d4176f19fb8/fairbairnecologiesofchangeviolenceagainstwomenprevention.pdf (accessed on 6 March 2019).

81. Oakley, A. Subject Women; Pantheon Books: New York, NY, USA, 1981.

82. Babbie, E.R.; Benaquisto, L. Fundamentals of Social Research; Scarborough: Toronto, ON, Canada, 2002.

83. Smith, D.E. The Everyday World as Problematic: A Feminist Sociology; Northeastern University Press: Boston, MA, USA, 1987.

84. Risman, B.J. Gender As a Social Structure: Theory Wrestling with Activism. Gend. Soc. 2004, 18, 429-450. [CrossRef]

85. Letherby, G. Feminist Research in Theory and Practice; McGraw-Hill Education: New York, NY, USA, 2003.

86. Stacey, J. Can there be a feminist ethnography? Women Stud. Int. Forum 1988, 11, 21-27. [CrossRef]

87. Opie, A. Qualitative Research, Appropriation of the 'Other' and Empowerment. Fem. Rev. 1992, 40, 52-69. [CrossRef]

88. Karaian, L. Policing 'sexting': Responsibilization, respectability and sexual subjectivity in child protection/crime prevention responses to teenagers' digital sexual expression. Theor. Criminol. 2013, 18, 282-299. [CrossRef]

89. Sutherland, G.; McCormack, A.; Easteal, P.L.; Holland, K.; Pirkis, J. Media guidelines for the responsible reporting of violence against women: A review of evidence and issues. Aust. Journal. Rev. 2016, 38, 5-17.

90. Gilmore, J. Fixed It; Penguin Books: Melbourne, Australia, 2019.

91. AlJazeera. Feminists on Twitter Say \#Solidarity Is for White Women. Available online: http://stream.aljazeera. com/story/201308122356-0022973 (accessed on 12 August 2013).

92. Feeny, N. The Most Powerful \#YesAllWomen Tweets. 2014. Available online: http://time.com/114043/ yesallwomen-hashtag-santa-barbara-shooting/ (accessed on 1 February 2015).

93. Teotonio, I. Women Find Power in \#Been Raped Never Reported Hashtag. Toronto Star. Available online: http: //www.thestar.com/life/2014/11/05/women_find_power_in_beenrapedneverreported_hashtag.html (accessed on 5 November 2014).

94. Wade, L.; Sharp, G. Sociological images: Blogging as public sociology. Soc. Sci. Comput. Rev. 2013, 31, 221-228. [CrossRef]

95. Barak, A. Sexual Harassment on the Internet. Soc. Sci. Comput. Rev. 2005, 23, 77-92. [CrossRef] 
96. Megarry, J. Online incivility or sexual harassment? Conceptualising women's experiences in the digital age. Women Stud. Int. Forum 2014, 47, 46-55. [CrossRef]

97. Lumsden, K.; Morgan, H. Media framing of trolling and online abuse: Silencing strategies, symbolic violence, and victim blaming. Fem. Media Stud. 2017, 17, 926-940. [CrossRef]

98. Edwards, D. Ending Violence One Green Dot at a Time: Instructor Manual. 2009. Available online: https: //www.anokatech.edu/StudentServices/GetInvolved/ \{\}/media/E5C4D63431314AA08BC351DDD0C191FC. ashx (accessed on 12 April 2020).

99. Moynihan, M.M.; Eckstein, R.P.; Banyard, V.L.; Plante, E.G. Facilitator's Guide for Bringing in the Bystander: A Prevention Workshop for Establishing a Community of Responsibility, Revised Version; University of New Hampshire: Durham, NH, USA, 2010.

100. Christensen, H.S. Political Activities on the Internet: Slacktivism or Political Participation by Other Means? Available online: https:/firstmonday.org/article/view/3336/2767 (accessed on 10 July 2020).

101. Fairbairn, J. Rape threats and revenge porn: Defining sexual violence in the digital age. In E-Girls, E-Citizens: Putting Technology Theory, Policy, Education into Dialogue with Girls' and Young Women's Voices; Bailey, J., Steeves, V., Eds.; University of Ottawa Press: Ottawa, ON, Canada, 2015; pp. 229-251.

102. Powell, A.; Henry, N. Technology-Facilitated Sexual Violence Victimization: Results From an Online Survey of Australian Adults. J. Interpers. Violence 2016, 34, 3637-3665. [CrossRef]

103. Palasinski, M. The roles of monitoring and cyberbystanders in reducing sexual abuse. Comput. Hum. Behav. 2012, 28, 2014-2022. [CrossRef]

104. van Bommel, M.; van Prooijen, J.W.; Elffers, H.; van Lange, P.A. Intervene to be seen: The power of a camera in attenuating the bystander effect. Soc. Psychol. Personal. Sci. 2014, 5, 459-466. [CrossRef]

105. Lewis, R.; Rowe, M.; Wiper, C. Online Abuse of Feminists as An Emerging form of Violence Against Women and Girls. Br. J. Criminol. 2016, 57, 1462-1481. [CrossRef]

(C) 2020 by the author. Licensee MDPI, Basel, Switzerland. This article is an open access article distributed under the terms and conditions of the Creative Commons Attribution (CC BY) license (http://creativecommons.org/licenses/by/4.0/). 